\title{
Pharmacogenetic Advances in Cardiovascular Medicine: Relevance to Personalized Medicine
}

\author{
Inna Y. Gong • Richard B. Kim
}

Published online: 8 January 2013

(C) Springer Science + Business Media New York 2013

\begin{abstract}
The field of pharmacogenetics aims to more fully delineate the genetic basis of interindividual variation in pharmacokinetics, pharmacodynamics, and adverse drug reactions. Indeed, remarkable progress has been made in the past decade, so that we now have a far greater appreciation for the genetic contribution to observed variation in drug responsiveness. We are now starting to witness the translation of findings observed in pharmacogenetic studies to their implementation for patient care as personalized medicine, where an individual patient's genetic makeup is used to guide drug selection and dosing. Many widely utilized cardiovascular drugs have now been linked to commonly occurring heritable genetic variations referred to as single nucleotide polymorphisms to variation in observed efficacy as well as risk for toxicity. As such, the current report outlines clinically relevant evidence supporting the important role of pharmacogenetics to the treatment of patients with cardiovascular disease.
\end{abstract}

Keywords Pharmacogenetics - Cardiovascular medicine . Personalized medicine $\cdot$ Interindividual variability $\cdot$ Drug response

\author{
I. Y. Gong · R. B. Kim \\ Division of Clinical Pharmacology, University of Western \\ Ontario, London, ON, Canada \\ e-mail: igong@uwo.ca \\ I. Y. Gong - R. B. Kim \\ Department of Physiology and Pharmacology, University \\ of Western Ontario, London, ON, Canada \\ Present Address: \\ I. Y. Gong · R. B. Kim $(\bowtie)$ \\ University Hospital, 339 Windermere Road BLL-115, London, \\ ON N6A5A5, Canada \\ e-mail: richard.kim@lhsc.on.ca
}

\section{Introduction}

Clinical trials have clearly demonstrated the therapeutic benefit for many cardiovascular agents; however, some patients, even on the same dose, exhibit loss of efficacy or higher risk of toxicity. We know that, while an average dose of a medication can benefit a large proportion of the patient population, the one-size-fits-all dosing regimen disregards the importance of identified variation in drug metabolism, transport, and response pathways known to exist in any given population. Not surprisingly, preventable adverse drug reactions (ADRs) often occur in subsets of susceptible patients. Interindividual differences in drug response are multifactorial and may be explained by an array of factors including environmental, genetic, comorbidities, and drug-drug interactions.

Advances in the field of pharmacogenetics over the past decade have dramatically improved our understanding of the impact of genetic variability to observed variation in drug response and toxicity. Accordingly, we now have the capability to use an individual genetic makeup in combination with clinical variables to choose appropriate drug therapy and dosages in an a priori fashion. Therefore, the field of pharmacogenetics has significant implication for optimizing cardiovascular drug therapy, considering the large proportion of patients with cardiovascular disease requiring pharmacotherapy.

Associations of genetic variations with drug response largely fall within two categories (Fig. 1): polymorphisms that affect drug pharmacokinetics by introducing variability in systemic drug exposure; and polymorphisms that affect pharmacodynamics by affecting the drug's ability to act at the target site. Not surprisingly, for the most part, candidate gene approaches have been used to identify single nucleotide polymorphisms (SNPs) in genes suspected to influence 

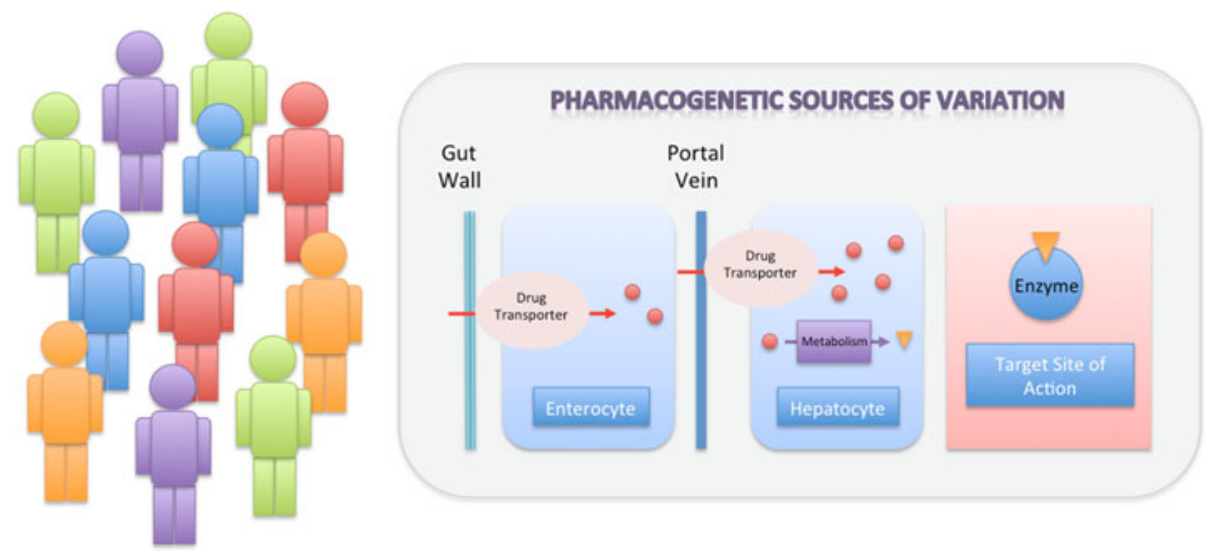

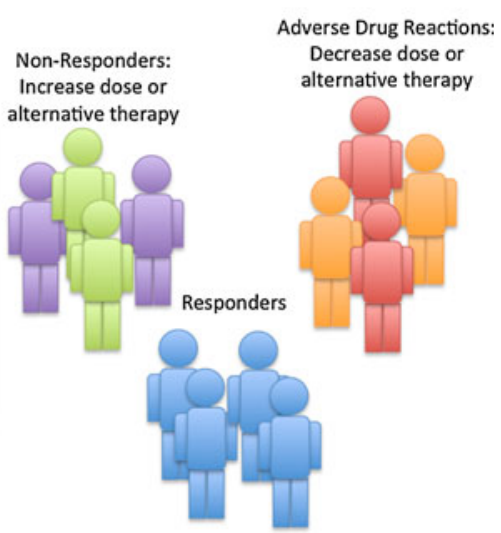

Fig. 1 Pharmacogenetic determinants of interindividual variability in cardiovascular therapy. Genetic variability in drug transporter and metabolizing enzymes expressed at the level of enterocytes and hepatocytes affect pharmacokinetics and overall disposition. Genetic variability in the gene(s) encoding the drug's pharmacological target affects pharmacodynamics. Identified genetic variants confer altered drug sensitivity, response, and toxicity, allowing classification of patients as responders or nonresponders

Table 1 Summary of current evidence in cardiovascular pharmacogenetics

\begin{tabular}{|c|c|c|c|c|c|c|}
\hline Drug & Drug class & Description & Gene(s) & Category & Problem & Clinical implementation \\
\hline Warfarin & $\begin{array}{l}\text { Anti- } \\
\text { coagulant }\end{array}$ & $\begin{array}{l}\text { Variation in dose } \\
\text { requirement for } \\
\text { achieving and } \\
\text { maintaining INR in } \\
\text { therapeutic range }\end{array}$ & $\begin{array}{l}\text { CYP2C9, } \\
\text { VKORC1 }\end{array}$ & PK, PD & $\begin{array}{l}C Y P 2 C 9 * 2, C Y P 2 C 9 * 3, \\
\text { VKORC1 } 1639 \mathrm{G}>\mathrm{A} \text { carriers } \\
\text { have increased sensitivity to } \\
\text { warfarin }\end{array}$ & $\begin{array}{l}\text { Dose reduction for loss-of- } \\
\text { function variant carriers }\end{array}$ \\
\hline Clopidogrel & $\begin{array}{l}\text { Anti- } \\
\text { platelet }\end{array}$ & $\begin{array}{l}\text { Variation in antiplatelet } \\
\text { response leading to } \\
\text { resistance in a subset of } \\
\text { patients }\end{array}$ & CYP2C19 & PK & $\begin{array}{l}C Y P 2 C 19 * 2 \text { and } C Y P 2 C 19 * 3 \\
\text { carriers have insufficient } \\
\text { active metabolite formation } \\
\text { leading to resistance }\end{array}$ & $\begin{array}{l}\text { Dose increase or consider } \\
\text { newer antiplatelet agents } \\
\text { for loss-of-function } \\
\text { variant carriers }\end{array}$ \\
\hline Simvastatin & Statin & $\begin{array}{l}\text { Variation in lipid lowering } \\
\text { efficacy and increased } \\
\text { risk of myopathy }\end{array}$ & OATP1B1 & PK & $\begin{array}{l}O A T P 1 B 1 * 5 \text { carriers have } \\
\text { increased systemic exposure } \\
\text { and risk of myotoxicity }\end{array}$ & $\begin{array}{l}\text { Avoid using high-dose or } \\
\text { consider using } \\
\text { alternative statins }\end{array}$ \\
\hline Metoprolol & $\beta$-Blocker & $\begin{array}{l}\text { Variation in blood } \\
\text { pressure lowering } \\
\text { response and reduction } \\
\text { in cardiovascular events }\end{array}$ & CYP2D6 & PK & $\begin{array}{l}C Y P 2 D 6 * 4 \text { carriers have } \\
\text { increased sensitivity to } \\
\text { metoprolol }\end{array}$ & $\begin{array}{l}\text { Dose reduction for loss-of- } \\
\text { function variant carriers }\end{array}$ \\
\hline Perindopril & $\begin{array}{l}\text { ACE- } \\
\text { inhibitor }\end{array}$ & $\begin{array}{l}\text { Variation in blood } \\
\text { pressure lowering } \\
\text { response and reduction } \\
\text { in cardiovascular events }\end{array}$ & $\begin{array}{l}A G T R 1, \\
\quad B D K R B 1\end{array}$ & PD, PD & $\begin{array}{l}\text { Variant carriers have reduced } \\
\text { cardiovascular benefit }\end{array}$ & $\begin{array}{l}\text { Requires additional } \\
\text { validation }\end{array}$ \\
\hline
\end{tabular}

$A C E$ angiotensen converting enzyme, $A G T R 1$ angiotensin II receptor 1, BDKRB1 bradykinin B1 receptor, CYP cytochrome $\mathrm{P} 450, O A T P$ organic anion transporting polypeptide, $P D$ pharmacodynamics, $P K$ pharmacokinetics, VKORC1 vitamin $\mathrm{K}$ epoxide reductase subunit 1

variation in response. On the other hand, genome-wide association studies (GWAS) for drug response represent an unbiased screen across the entire genome and may inform novel pathways of relevance to ADRs or therapeutic response.

We now see a number of pharmacogenetic linkages for a number of medications, some of which have resulted in FDA label changes to incorporate guidance on consideration of genetic information during treatment. The present review highlights the genetic determinants of commonly used cardiovascular drugs (Table 1), and how the use of such information may enhance patient care in a clinical setting.

\section{Oral Anticoagulants}

\section{Warfarin}

The vitamin $\mathrm{K}$ antagonist warfarin is a common oral anticoagulant prescribed in North America for stroke prevention in atrial fibrillation (AF) patients and thromboembolism prophylaxis in venous thromboembolism (VTE) [1]. However, warfarin therapy is particularly challenging due to marked and often unpredictable interindividual dosing variation (up to 20 -fold) to reach and maintain adequate anticoagulation. Not surprisingly, its clinical use is associated with ADRs, mainly 
in the form of bleeding events; in fact, warfarin was recently reported to account for one-third of hospitalizations in the elderly [2]. For most indications, optimal warfarin therapy is achieved by maintaining the international normalized ratio (INR) within a narrow therapeutic range of 2-3. An insufficient warfarin dose leads to a lack of antithrombotic effect while over-anticoagulation is associated with elevated bleeding risk. Aside from demographic (age, gender, weight) and clinical variables (renal or hepatic disease, diet, drug-drug interactions), pharmacogenetics explains a large portion of the observed variability in warfarin dose requirement [3].

\section{CYP2C9}

Warfarin is administered as a racemic drug; $S$-warfarin is 3-5 times more potent than $R$-warfarin. The clearance and thus pharmacokinetics of warfarin is largely dependent on the metabolic pathways of each enantiomer. While CYP1A2, CYP3A4, and CYP2C19 are enzymes that convert the $R$-warfarin to its inactive metabolite in varying extents, CYP2C9 is the primary enzyme responsible for metabolism of $S$-warfarin. As such, candidate gene studies have consistently shown that CYP2C9 polymorphisms significantly affect warfarin sensitivity [4]. In particular, common CYP2C9*2 and $* 3$ variant alleles result in decreased enzymatic activity (30 and $90 \%$ reduction, respectively) compared to the wild-type allele [5]. The clinical implication for these SNPs is lower therapeutic dose requirement, increased time to stable anticoagulation and increased bleeding risk due to greater rate of overanticoagulation [6]. A large meta-analysis of 39 studies $(n=7,907)$ demonstrated that maintenance dose for CYP2C $9 * 2$ and $* 3$ homozygous patients were 36 and $78 \%$ lower, respectively, as compared to wild-type patients [7].

\section{VKORC1}

$S$-warfarin inhibits the vitamin $\mathrm{K}$ epoxide reductase, encoded by $V K O R C 1$, the enzyme responsible for recycling oxidized vitamin $\mathrm{K}$ to the reduced form, an essential cofactor for $\gamma$-glutamyl-carboxylase carboxylation (GGCX) in clotting factor II, VII, IX and X activation [8]. Common genetic variants in VKORCl result in altered warfarin sensitivity while rare polymorphisms result in warfarin resistance [9]. Of note, the common promoter SNP (VKORC1 1639G >A, rs9923231) is thought to be the causative variation responsible for the greater warfarin sensitivity, resulting in lowered dose requirement [10].

\section{Other SNPs}

In addition to $C Y P 2 C 9$ and $V K O R C 1$ polymorphisms, SNPs in other genes have been studied as potential contributors to warfarin response. These genes include $G G C X$, calumenin $(C A L U)$, apolipoprotein $\mathrm{E}(A p o E)$ as well as multidrug resistance protein $(A B C B 1)$ [11]. However, the impact of these polymorphisms on warfarin response has generally been minimal or none at all. An exception to this is the growing importance of the CYP4F2 1297C $>\mathrm{T}$ genotype, whereby several retrospective studies have demonstrated that variant $\mathrm{T}$ carriers (rs2108622) require $1 \mathrm{mg}$ more than wild-type C carriers [12]. Moreover, CYP4F2 is the metabolizing enzyme of vitamin $\mathrm{K}$ accounting for the pharmacological basis of the dose difference [13]. However, the CYP4F2 genotype only accounts for a small portion of the observed maintenance dose variability $(0-4 \%)$ [14]. These findings were confirmed by recent GWASs, where polymorphisms in CYP2C9 and VKORC1 were the only genetic markers identified to influence warfarin dosing, while the $C Y P 4 F 2$ genotype was only significant after adjusting for $C Y P 2 C 9$ and VKORC1 [15].

\section{Clinical Applicability of SNPs}

$C Y P 2 C 9 * 2, C Y P 2 C 9 * 3$ and $V K O R C 11639 \mathrm{G}>\mathrm{A}$ variant carriers are at an increased risk of over anticoagulation (INR > 4) and bleeding as well as delayed time to therapeutic efficacy. Based on these findings, the FDA approved a new label for warfarin in 2007 advising physicians to consider pharmacogenetic testing for patients requiring warfarin. Many dosing algorithms have been developed to predict warfarin dose requirement using CYP2C9, VKORC1, and CYP4F2 SNPs and clinical parameters [16]. The majority of these studies have focused on the effect of genetic variation on warfarin dose during maintenance phase of anticoagulation. However, warfarin initiation is arguably the most challenging therapeutic phase where risk of hemorrhage and recurrent VTE are greatest [17]. Moreover, we and others demonstrated that CYP2C9 and VKORC1 modulate warfarin response even during early anticoagulation [18]. Accordingly, our group recently demonstrated that initiation with the novel pharmacogenetics-based protocol (WRAPID) incorporating loading and maintenance dosing produces a safe, effective, and consistent anticoagulation in AF and VTE patients irrespective of genotype [19].

\section{Clinical Implementation}

There is a strong association between $C Y P 2 C 9$ and VKORC1 SNPs with warfarin response and dose. However, the widespread use of pharmacogenetics-based warfarin dosing remains has not yet been achieved, in part related to concerns regarding costs associated with pharmacogenetic testing and additional clinical evidence to support superiority of a pharmacogenetics-based approach. Recently, the 
COUMAGEN-II trial showed clear superiority of pharmacogenetics-based warfarin dosing over standard care with respective to time spent in therapeutic range and reduced occurrence of ADRs [20 ${ }^{\bullet}$. Additionally, a recent large scale community-based study found that genotyping during warfarin therapy reduced the hospitalization rate for bleeding or thromboembolic event by $30 \%$ compared to a historical control group [21]. A number of RCTs (www.clinicaltrials.gov; COAG, GIFT, EU-PACT) involving larger sample sizes are currently underway to more fully confirm such findings focusing on safety and efficacy of pharmacogenetics-based dosing compared to standard dosing. Given the extent of supportive evidence to date for warfarin, pharmacogeneticsbased warfarin dosing is likely to be widely implemented, particularly given the rapid improvement in genotyping technologies that has resulted in greater accuracy, turnaround time, and lower cost.

\section{New Oral Anticoagulants: Dabigatran and Rivaroxaban}

Dabigatran, a direct thrombin inhibitor, and rivaroxaban, a factor 10a inhibitor, are new oral anticoagulants recently approved for AF and VTE. Dabigatran etexilate is a prodrug, requiring bioactivation to active dabigatran by esterases while rivaroxaban undergoes metabolism predominantly by CYP2J2 and CYP3A4 [22]. Interestingly, both agents are substrates of P-glycoprotein (ABCB1) while rivaroxaban is also a substrate of breast cancer resistance protein (BCRP) [23]. Very recently, a genomewide subanalysis of the RE-LY trial demonstrated that a common variant in the carboxylesterase 1 (CESI) gene (rs2244613) was associated with dabigatran-related bleeding events (unpublished data). The polymorphism is thought to attenuate dabigatran formation resulting in lowered systemic exposure and reduced bleeding risk, indicating the potential for pharmacogenetics-based dosing. Further studies are needed to confirm these findings in addition to identification of additional genetic variations in candidate genes such as $A B C B 1$ and $B C R P$ to determine SNPs capable of modulating their efficacy and toxicity.

\section{Antiplatelets}

Aspirin

Aspirin is commonly prescribed for prevention of cardiovascular events. Aspirin irreversibly binds and inactivates cyclooxygenase (COX) 1 and 2 in platelets, and thereby reduce platelet aggregation [24]. The term of aspirin resistance has been coined to note the occurrence of cardiovascular events, presumably related to suboptimal antiplatelet inhibitory effect in patients prescribed with therapeutic doses of aspirin. However, classification of aspirin resistance has been highly controversial with prevalence of 5-60\% depending on the population and ex vivo response measurement used; a patient defined as a non-responder in one test would be normal in another [25]. Therefore, it has been challenging to interpret the relevance of genetic markers associated with aspirin response.

\section{PTGS1}

Since COX1 is the direct pharmacological target of aspirin, considerable amount of focus has been on the COX1 encoding gene, PTGSI. However, results of such studies have been variable. Although genetic polymorphisms in this gene have been linked to greater platelet aggregation in some studies, many others failed to replicate such an effect or find an association with cardiovascular events such as myocardial infarction (MI) [26].

\section{Other SNPS}

Several other genes encoding platelet activation pathway proteins have been linked to aspirin antiplatelet response. The ITGB3 gene encodes GPIIIa protein and carriers of the risk allele (rs5918) appear to confer elevated risk of MI, arterial and venous thrombosis. However, other studies in this regard have been conflicting [26]. A recent study found carriers of an intronic SNP in the PEARl gene (rs12041331) corresponded to higher aspirin response [27]. Additionally, a SNP in the LPA gene (rs3798220) determined plasma levels of apolipoprotein A and associated with differential aspirin efficacy in a large placebo-controlled trial [28].

\section{Clinical Implementation}

The extent of clinically relevant genetic markers and their role to aspirin response remain to be defined. The lack of consistent associations indicates it may be premature to include genetic testing for aspirin therapy, at least based on currently published genetic markers. It addition, a key impediment has been the lack of a standardized antiplatelet response measurement assay for aspirin prescribed patients.

\section{Clopidogrel}

Antiplatelet therapy with thienopyridine is an important therapeutic intervention for the prevention of ischemic events in patients with high-risk cardiovascular disease, particularly for those undergoing percutaneous coronary intervention (PCI) [29]. Clopidogrel is the most widely prescribed thienopyridine known to exert its pharmacological effect by irreversibly binding to $\mathrm{P} 2 \mathrm{Y}_{12}$ receptors on platelets, thereby diminishing platelet aggregation [30]. Although benefits from 
clopidogrel has been widely documented in large clinical trials, marked interpatient variation in platelet responsiveness has meant that $21 \%$ of patients (termed nonresponders) remain at risk for coronary artery and stent thrombosis [31].

\section{CYP2C19}

Clopidogrel is a prodrug and its clinical efficacy is a function of the amount of enzymatically derived active thiol metabolite formed (H4) [32]. While most of the prodrug undergoes hydrolysis to an inactive metabolite, clopidogrel bioactivation is a two-step process catalyzed by several CYP isozymes [33]. Both metabolic steps leading to $\mathrm{H} 4$ formation have been shown to be predominantly dependent on CYP2C19, and to a lesser extent CYP3A4 [33].

A number of studies have examined the influence of genetic variation in CYP enzymes on clopidogrel antiplatelet response. The most consistent finding is that CYP2C19*2 (rs4244285) and CYP2C19*3 (rs4986893) loss-of-function SNPs results in lower platelet inhibition, high on-treatment platelet reactivity and, consequently, an increased risk of major cardiovascular events, particularly stent thrombosis in PCI patients [34]. A meta-analysis including nine studies $(n=9,685)$ reported a gene-dose effect for variant carriers; one reduced function allele carrier had a hazard ratio of 1.57 (95\% confidence interval 1.13-2.16) for a composite of cardiovascular endpoints while carriers of two reduced function alleles had an even greater risk (hazard ratio 1.76, 1.24-2.5) [34]. Another common $C Y P 2 C 19$ polymorphism (*17, rs3758581) results in increased enzyme activity, greater efficacy, and better cardiovascular outcomes at the expense of increased bleeding risk [35]. These findings prompted the FDA to update the clopidogrel label with a boxed warning for cautious use amongst CYP2C19 reduced function carriers.

\section{PON1}

Bouman et al. [36] recently demonstrated that a non-CYP enzyme, paraoxonase-1 (PON1) was the key determinant of clopidogrel active metabolite formation. They showed plasma PON1 activity as well as the Q192R SNP (rs662) in PON1, but not CYP2C19 SNPs was predictive of antiplatelet response and risk for stent thrombosis in clopidogrel-treated patients. However, several subsequently published studies of large sample sizes refuted the role PON1 in clopidogrel response and cardiovascular outcomes [37]. Mechanistically, we and Dansette et al. [38•, 39] demonstrated that PON1, unlike CYP2C19, is incapable of generating $\mathrm{H} 4$ active metabolite. Our study demonstrated that CYP2C19 loss-of-function genotype was a major determinant of $\mathrm{H} 4$ exposure corresponding to lowered ADP-induced antiplatelet response, while $P O N 1$ failed to play any role.

\section{$A B C B 1$}

Clopidogrel has been demonstrated to be a substrate of P-glycoprotein, which limits the extent of its bioavailability. Not surprisingly, the $A B C B 1 \quad 3435 \mathrm{C}>\mathrm{T}$ SNP (rs1045642) has been shown to result in lower peak concentrations of clopidogrel and its active metabolite [40]. However, the definitive role of this SNP on clopidogrel antiplatelet response remains controversial. While Mega et al. [41] reported that the elevated cardiovascular risk of CYP2C19 variant allele carriers was accentuated in presence of homozygous $3435 \mathrm{C}>\mathrm{T}$ genotype, other studies could not replicate this finding [42].

$P 2 Y_{12}$

Clopidogrel exerts its pharmacodynamics effects by inhibition of $\mathrm{P}_{2} \mathrm{Y}_{12}$ receptor on platelets. Recently, Ziegler et al. [43] reported a fourfold increase in cerebrovascular events in patients possessing the $34 \mathrm{C}>\mathrm{T}$ ( $\mathrm{rs} 6809699$ ) variant while another variant, 52G $>\mathrm{T}$ (rs6785930), confers clopidogrel resistance following PCI. However, other studies have failed to show the same trend for antiplatelet response and cardiovascular events [44].

\section{Other SNPS}

CYP2C19 undoubtedly predicts cardiovascular outcomes in patients treated with clopidogrel following PCI, yet it is thought to represent only a portion of the observed variation in antiplatelet response. A GWAS demonstrated that clopidogrel platelet aggregation was highly heritable $\left(r^{2}=0.73\right)$ in an Amish population [45]. However, the CYP2C19*2 SNP only accounted for $12 \%$ of the interindividual variation, indicating that other genetic markers affecting efficacy remain to be identified to explain the large heritable component of clopidogrel response. More recently, the Scripps Clinic conducted whole genome sequencing in 392 patients on clopidogrel and found two novel genes $A T P 2 B 2$ and TIAM2 to predict poor platelet response (unpublished data).

\section{Clinical Implementation}

Clopidogrel resistance and the lack of adequate therapeutic efficacy is a major concern, thus identification of resistant patients prior to treatment is of great value for favorable outcomes. Although there is ample evidence linking CYP2C19 with cardiovascular outcomes in PCI patients, RCTs assessing the benefit of genotyping for CYP $2 C 19$ over standard care has yet to be conducted. One recent RCT using point-of-care $C Y P 2 C 19 * 2$ genotyping showed that such genetic information led to better prediction of 
antiplatelet response in a real world setting, indicating that personalized clopidogrel therapy may be effective in improving efficacy [46]. Accordingly, a number of institutions (Vanderbilt University Medical Centre, Scripps Clinic) adopted routine $C Y P 2 C 19$ genotyping for patients undergoing PCI [47•]. Conversely, although several small prospective trials have restored diminished $\mathrm{H} 4$ exposure and poor antiplatelet response in $C Y P 2 C 19$ variant carriers by increasing clopidogrel loading and maintenance dose [48], recent larger studies failed to overcome the reduced antiplatelet response in individuals harboring $C Y P 2 C 19 * 2$ variant alleles [49]. This indicates that clopidogrel potency at the $\mathrm{P} 2 \mathrm{Y} 2{ }_{12}$ receptor is likely inadequate for $C Y P 2 C 19$ variant carriers. Accordingly, the Clinical Pharmacogenetics Implementation Consortium suggested that newer antiplatelet agents with greater affinity and potency (prasugrel and ticagrelor) should be considered for carriers of one or two loss-of-function variant alleles [50]. Indeed, $C Y P 2 C 19 * 2$ carriers were more likely to switch to prasugrel due to high ontreatment platelet reactivity [51]. Current ongoing studies include the GIANT trial which will assess the clinical efficacy of using high-dose clopidogrel for $C Y P 2 C 19 * 2$ carriers and the RAPID-STEMI trial that will evaluate efficacy of either high-dose clopidogrel or switching to prasugrel for $C Y P 2 C 19 * 2$ and $A B C B 13435$ TT carriers.

\section{New Antiplatelets: Prasugrel and Ticagrelor}

Neither agent requires extensive bioactivation by CYP2C19. Thus, CYP2C19 genetic variation has not been demonstrated to affect cardiovascular outcomes in subanalysis of the TRITON-TIMI (prasugrel) or the PLATO (ticagrelor) trial [52]. However, we note that CYP3A4 and CYP2B6 are responsible for bioactivation of prasugrel to its active form, and the influence of polymorphisms in these enzymes to prasugrel platelet efficacy remains to be delineated. An important consideration of prasugrel use over clopidogrel is that, although it proved more efficacious than clopidogrel, this is at the price of increased bleeding risk. Similarly, ticagrelor use over clopidogrel is complicated by the finding that ticagrelor was as effect as clopidogrel across all international centres of PLATO trial except for North America.

\section{Lipid-Lowering Drugs}

\section{Statins}

The 3-hydroxy-3-methylglutaryl-coenzyme A reductase (HMGCR) is the rate-limiting step for cholesterol biosynthesis in the liver. The cholesterol lowering class of statin drugs exerts its pharmacological effect by inhibiting
HMGCR, reducing circulating cholesterol and low-density lipoprotein (LDL). Accordingly, statins are widely prescribed for primary and secondary prevention of cardiovascular disease. Although clinical effectiveness of statins has been proven in large RCTs, substantial interindividual variability has meant that a subset of patients fail to attain sufficient cholesterol reduction and prevention of cardiovascular events [53]. Thus, pharmacogenomic studies have been conducted to gain insight into genetic basis of response and tolerability.

\section{SLCO1BI}

Statins are known to be substrates of the solute carrier organic anion transporting polypeptides 1B1 (OATP1B1), encoded by the $S L C O 1 B 1$ gene, expressed on the basolateral membrane of hepatocyte facilitating the hepatocellular uptake of statins from the portal circulation [54]. In 2001, our group was the first to identify and create the nomenclature (from $* 1$ a to $* 14$, which has since been widely adopted) for $S L C O 1 B 1$, which at that time was known as OATP-C (also known as SLC21A6, OATP2, and LST1) as well as deduce their functional relevance [55]. In particular, the $S L C O 1 B 1 * 5$ variant conferred reduced membrane localization of OATP1B1, and clinical studies have consistently linked this SNP to altered statin disposition, in terms of decreased hepatocellular uptake which then results in enhanced systemic exposure. On the other hand, the $S L C O 1 B 1^{*} 1 b$ genotype has been associated with lower plasma statin exposure. However, controversy exists for the relevance of $S L C O 1 B 1$ variants in predicting LDLlowering efficacy and requires further assessment in a large patient cohort [56, 57].

It should be noted that statin-use may result in unexpected muscle toxicity ranging from mild myalgia to the life-threatening rhabdomyolysis. Indeed, the most convincing data to date comes from a recent GWAS that identified $S L C O 1 B 1 * 5$ allele as the single most important predictor of simvastatin-induced myopathy [58]. In that study, the odds ratio for myopathy-risk owing to $S L C O 1 B 1 * 5$ was found to be 4.5 for heterozygous carriers and 16.9 for homozygous carriers [58]. Subsequently, the $S L C O 1 B 1 * 5 \mathrm{SNP}$ has been shown to predict statin-related ADRs (discontinuation, creatine kinase elevation and myalgia) and statin intolerance (dose adjustment, statin switching) in patients prescribed with atorvastatin, simvastatin, or pravastatin [59, 60]. Overall, these data provide sufficient evidence to indicate that SNPs in SLCO1B1 alter pharmacokinetics and pharmacodynamics and contribute to statin-induced ADRs. It is noteworthy that myopathy risk is statin-dependent, the greatest risk was observed with simvastatin followed by atorvastatin, pravastatin, rosuvastatin, and fluvastatin [61]. Genotyping for SLCO1B1 
polymorphisms may contribute to delivering optimal cholesterol lowering effects while reducing the risk of statininduced myopathy.

\section{HMGCR and APOE}

The pharmacodynamic response to statins in terms of LDL reduction appears to be affected genetic variations in $H M G C R$ and APOE. Carriers of the HMGCR $\mathrm{H} 7$ haplotype, defined by three intronic SNPs (rs17244841, rs3826662, and rs17238540) experienced 11-19\% lower statin sensitivity, as measured by LDL reduction [62]. However, these findings were not replicated in a GWAS with atorvastatin response [63॰]. The effect of $A P O E$ haplotypes (rs429358 and rs7412 define 3 haplotypes) on statin response is controversial. The first GWAS study on statin response showed that $A P O E$ polymorphisms related to LDL lowering response, where the response was greatest for the $\varepsilon 2$ haplotype and variant carriers had attenuated efficacy [63॰]. However, a recent meta-analysis failed to confirm these associations [64]. Thus, the impact of $H M G C R$ and APOE genetic variations on lipid-lowering statin response remains to be further evaluated.

\section{KIF6}

The kinesin-like family 6 (KIF6) gene was identified to predict incidence of coronary artery disease (CAD) and may represent a novel pathway underlying cardiovascular disease [65]. Indeed, carriers of the rs20455 SNP attained greater cardiovascular benefit than noncarriers in some studies [66]. However, a subsequent meta-analysis of large statin trials showed no association of this SNP with risk of CAD [67]. Similarly, no differential relationship was found with statin efficacy in carriers and noncarriers. Additional studies are needed to explore the impact of KIF6.

\section{Other SNPs}

Rosuvastatin has been shown to be a substrate of the efflux transporter BCRP (encoded by $A B C G 2$ ), expressed on the apical membrane of hepatocytes. Indeed, the $A B C G 2$ $421 \mathrm{C}>\mathrm{A}$ polymorphism was associated with rosuvastatin pharmacokinetics and greater reduction in LDL [68]. The greater LDL reduction would be equivalent to doubling of the rosuvastatin dose. Atorvastatin and simvastatin are both metabolized by CYP3A4 and common polymorphisms in CYP3A4 may affect statin exposure and response. Statin use leads to subsequent upregulation of LDL receptor (LDLR) [69]. In a population of African ancestry, LDLR haplotype was associated with reduced statin efficacy. Carriers of the rs8014194 polymorphism in the CLMN gene, encoding the calmin protein of unknown function, had $3 \%$ greater reduction in total cholesterol compared to noncarriers in a combined GWAS analysis of three trials [70].

\section{Clinical Implementation}

The most supportive evidence for clinically relevant statin pharmacogenetics relates to drug transporter polymorphisms. Robust evidence for other genetic markers relating to statin response and myopathy risk is lacking and requires additional evaluation. For this reason, several groups have suggested for the use of genetic variations in transporters to guide statin dosing [58]. Although the association between $S L C O 1 B 1 * 5$ genotype and simvastatin-induced myopathy has been replicated in subsequent clinical studies, the same association for other statins is less compelling. As such, FDA recently changed the label for simvastatin to incorporate SLCO1B1-defined guidelines. It was recommended that prescribers should avoid $80 \mathrm{mg}$ simvastatin in homozygous $S L C O 1 B 1 * 5$ carriers in addition to consideration of an alternative statin.

\section{Beta Blockers}

$\beta$-Blockers are $\beta$-adrenergic receptor antagonists and important cardiovascular medicines for the management and treatment of hypertension, post-MI, heart failure (HF) and CAD. Therapeutic response to $\beta$-blockers has been measured using alterations in heart rate (HR), blood pressure (BP), and left ventricular ejection fraction (LVEF) and cardiovascular outcomes include rate of MI, death or HF [71]. As with many drugs discussed thus far, $\beta$-blockers have substantial interindividual variation in response and efficacy.

\section{CYP2D6}

CYP2D6 is responsible for the metabolism of various $\beta$-blockers; CYP2D6 extensively metabolizes metoprolol (70-80\%), while to a lesser extent for carvedilol, propranolol, and alprenolol [72]. Not surprisingly, the influence of CYP2D6 genetic variations on metoprolol pharmacokinetics has been the most extensively studied. CYP2D6 is extremely polymorphic with many alleles of decreased or complete loss-of-function. In $5-10 \%$ of Caucasians, CYP2D6 enzyme activity is lacking due to possession of two copies of nonfunctional alleles (poor metabolizers, PMs) [73]. Homozygous carriers of CYP2D6*4 (rs3892087) account for $75 \%$ of CYP2D6 PMs. Individuals with two functional alleles are classified as extensive metabolizers (EMs) while ultra-rapid 
metabolizers (UMs) possess carrying more than two functional copies of CYP2D6 gene.

The CYP2D6 PM phenotype has been shown to increase metoprolol plasma exposure by sevenfold during short-term and long-term therapy [74]. This also translates to differential pharmacodynamics, where PMs have greater reduction in $\mathrm{HR}$ and $\mathrm{BP}$ [75]. Moreover, $C Y P 2 D 6 * 4$ carriers had an increased risk of ADRs such as bradycardia during metoprolol treatment compared to noncarriers in large studies [76]. Conversely, UMs had significantly lower systemic metoprolol exposure and little therapeutic benefit. The CYP2D6 UM phenotype was linked to more frequent ventricular rhythm disturbance in acute MI patients. We note that, despite the consistent trend between CYP2D6 genotype and metoprolol exposure, not all studies demonstrate its association with increased ADR risk [77]. Nevertheless, dose adjustments for metoprolol should be considered for CYP2D6 PM individuals, particular those at risk for cardiovascular complications.

\section{ADRB 1}

$\beta$-Blockers primarily antagonize the $\beta 1$-adrenergic receptor (ADRB1). The two common SNPs, Ser49Gly (rs1891252) and Arg389Gly (rs1801253) are in linkage disequilibrium [78]. A meta-analysis of three studies encompassing 504 HF patients supported better LVEF outcome in homozygous Arg389 individuals treated with $\beta$-blockers [78]. Furthermore, homozygous Arg389 hypertensive patients treated with metoprolol obtained efficacy in terms of greater reduction in $\mathrm{HR}$ and $\mathrm{BP}$, but this trend was not found for other $\beta$-blockers $[79,80]$.

Evaluation of mortality and hospitalization in $\mathrm{HF}$ patients with Arg389Gly genotype has yielded variable findings. In the BEST study, a large RCT assessing efficacy of a novel $\beta$-blocker bucindolol found that homozygous Arg389 patients had significantly improved survival time and decreased rate of hospitalization [81]. In contrast, no association with Arg389Gly was found in the MERIT-HT trial in patients treated with metoprolol [82]. Similarly, no association was found for mortality in a prospective registry study of HF patients treated with various $\beta$-blockers [83]. It is plausible that the association of Arg389Gly with mortality is unique to bucindolol. More recently, AF patients carrying the Gly389 variant had more favorable response to $\beta$-blockers than Arg389 carriers [84]. Additional studies are needed to resolve these divergent findings.

The Gly49 genotype has been associated with improved response and favorable survival rates in patients treated with $\beta$-blockers [85]. However, these findings should be interpreted with caution as other studies could not replicate this association [86].

\section{ADRB2}

The three polymorphisms in the ADRB2 encoding $\beta 2$-adrenergic receptor are Gly16Arg (rs104213), Gln27Glu (rs1042714), and Thr164Ile (rs1800888). Clinical studies have generally failed to demonstrate an association of response with Gly16Arg genotype [87]. On the other hand, several studies found that Glu27 genotype was associated with better $\beta$-blocker response in terms of HR, and LVEF changes [88]. Moreover, possessing ADRB1 Arg389 and $A D R B 2$ Gln27 variant genotypes together was associated with twofold increase in mortality compared to other genotype groups in patients treated with carvedilol. In the same study, this association was not found with metoprolol [89]. In a study of HF patients, heterozygous Ile164 carriers treated with $\beta$-blockers had a twofold higher mortality rate [90].

\section{ADRA2C}

The function of $\alpha 2 \mathrm{c}$-adrenergic receptor is autoinhibition of norepinephrine release and therefore may affect $\beta$-blocker responsiveness. Individuals carrying the deletion polymorphism, del322-325, have been found to experience greater improvement in LVEF with metoprolol treatment while experiencing reduced efficacy in the BEST trial [81, 91]. The disparate effect of this genotype may be a function of pharmacological differences in bucindolol and metoprolol. In addition, this deletion in combination with the $A D B R 1$ Arg389Gly genotype has been associated with increased risk of HF in African-Americans [92].

\section{GRK5}

The G-protein receptor kinase (GRK5) desensitizes G-protein coupled receptors of $\beta$-adrenergic receptors. The Gln41leu variant is a gain-of-function polymorphism commonly found in patients of African descent. In AfricanAmericans, but not European-Americans, individuals homozygous for the Gln41 genotype receiving $\beta$-blocker treatment had significantly improved mortality benefit [93]. Additional prospective studies are needed to explain the ethnic differences in mortality associated with this genotype.

\section{KCNQ1}

Very recently, a trial of 860 patients demonstrated that those with $\mathrm{C}$-loop mutations in the $K C N Q 1$ gene attained the greatest therapeutic benefit from $\beta$-blocker therapy in terms of lowered risk of cardiac arrest or sudden death [94]. 
Clinical Implementation

CYP2D6 undoubtedly affects $\beta$-blocker metabolisms and PMs have sustained therapeutic effect and greater risk of ADRs due to significant increase in systemic exposure. This is particularly relevant for the widely prescribed $\beta$-blocker metoprolol. Very recently, the Pharmacogenetics Working Group advised prescribers to consider alternative $\beta$-blocker therapy or dose reduction for CYP2D6 PMs on metoprolol for $\mathrm{HF}$ and vice versa for UMs [95•]. In terms of pharmacodynamic markers, ADRB1 Arg389Gly genotype gene showed the most evidence for differential HR, $\mathrm{BP}$ and survival rates during $\beta$-blocker treatment. Thus, dose adjustment may be required for Gly389 carriers, particularly as more data become available supporting this notion.

\section{Angiotensin Converting Enzyme Inhibitors}

The clinical role of angiotensin-converting enzyme inhibitors (ACEi) is in the management of hypertension, stable $\mathrm{CAD}$, MI, and HF. Despite the beneficial effects documented in clinical trials, interindividual variability in responses such as BP has been demonstrated [96]. Accordingly, distinguishing patients that will most likely benefit from ACEi therapy may be essential for optimal cardiovascular therapy.

\section{ACE}

The renin-angiotensin system (RAS) is responsible for blood pressure regulation and electrolyte balance and therefore plays a pivotal role in cardiovascular health. ACEi competitively inhibits the conversion of angiotensin I into angiotensin II, leading to reduced vasoconstriction and water and salt retention. Perhaps the most extensively studied gene affecting ACEi response is $A C E$, particularly the insertion and deletion (I/D) genetic variant in intron 6 (rs4646994). This variant has been associated with significantly higher plasma concentrations of $\mathrm{ACE}$ and confers differential reduction of BP [26]. Subsequent sufficiently powered studies have shown no difference in $\mathrm{BP}$ reduction among $A C E \mathrm{I} / \mathrm{D}$ genotype groups. In the Rotterdam observational study, individuals of DD genotype had an increased 10-year mortality risk as compared to individuals with II genotype. However, this finding was not validated in the prospective trials GenHAT and PROGRESS [26]. In the PERGENE trial, all five polymorphisms in the $A C E$ gene evaluated failed to predict primary cardiovascular outcomes [97]. Currently, there is a lack of convincing evidence for the influence of the $A C E \mathrm{I} / \mathrm{D}$ variant on ACEi response, although there is compelling evidence for this genotype to higher occurrence of ACEiinduced cough [98].

\section{AGT}

Angiotensinogen (AGT) is the precursor to angiotensin I and the variant Met235Thr (rs699) has been linked to modulate plasma concentrations of AGT among hypertensive patients. In a large Rotterdam cohort, $A G T \mathrm{Thr} 235$ allele carriers were predicted to have an elevated risk of MI and stroke in ACEitreated patients [99]. In another study, mortality risk was higher for Thr235 allele carriers taking benazepril. Individuals homozygous for the novel variant identified in the $3^{\prime}$-untranslated region of $A G T$ (rs7079) was associated with enhanced BP reduction in response to benazepril therapy [100].

\section{AGTR1 and Other SNPs}

Haplotype assignment of the angiotensin II receptor 1 (AGTR1) gene resulted in a gene-dose effect on BP reduction. Specifically, the recent PERGENE trial in which 8,907 stable CAD patients were evaluated for 52 haplotype tagging SNPs in 12 candidate genes for perindopril response, two polymorphisms in the AGTR1 gene (rs275651 and rs5182) and one in the bradykinin B1 receptor (BDKRB1) (rs12050217) were associated with a reduction in perindopril's cardiovascular benefit. [97]. A pharmacogenetics scoring system developed based on these SNPs successfully predicted the reduction in treatment benefit to perindopril in a stepwise manner as the number of variants increased.

\section{Clinical Implementation}

Findings of the PERGENE trial illuminates the usage of pharmacogenetics to guide individualized ACEi therapy. However, additional studies are needed to replicate the findings for perindopril and other ACEis.

\section{Antiarrhythmic Drugs}

Antiarrhythmic drugs are an important class of drugs used to manage cardiac arrhythmias, which contribute significantly to morbidity and mortality. Various calcium-channel blockers including verapamil, diltiazem, and digoxin are known ABCB1 substrates, an efflux drug transporter with broad substrate specificity [101]. Polymorphisms in $A B C B 1$ have been linked to altered pharmacokinetics of these agents at varying degrees, although no reports have shown differential outcomes or toxicity [101]. CYP2D6 PMs have an elevated risk of toxicity induced by the sodium-channel blocker flecainide, and the Pharmacogenetics Working 
Group recommends dose reduction by $50 \%$ in addition to monitoring response (ECG) [95•]. Similarly, propafenone is also metabolized by CYP2D6 and carriers of the CYP2D $6 * 4$ genotype have enhanced suppression of arrhythmias and toxicity; thus, dose reduction was also suggested for CYP2D6 PMs [95•].

\section{Conclusions}

Interindividual variation in drug exposure and efficacy lead to subsets of patients experiencing drug-related toxicities or inadequate therapeutic benefit. The one-dose-fits-all paradigm for drug therapy is increasingly recognized as inappropriate for many drugs in clinical use. Alternative paradigm for pharmacotherapy pertains to individualized therapies. In the past decade, substantial progress has been made linking commonly occurring genetic variants to cardiovascular treatment response. Despite this, pharmacogenetics-guided care is still in its infancy, as most centres have not implemented this approach to routine clinical practice. However, as the cost of genotyping continues to decline while the extent of clinical evidence supporting pharmacogenetics-based approach rises, there is little doubt that implementation of pharmacogenetics-guided personalized medicine will result in reduced incidence of ADRs, and greater likelihood of therapeutic benefit. Indeed, for drugs where pharmacogenetics-guided care has been shown to be noninferior, and potentially superior to standard care, such an approach should be implemented and further studied in a prospective fashion to show the overall merit of pharmacogenetics to enhancing patient care, reducing ADRs and health care costs in the real-world setting. We also recognize that, for many drugs, clinical decision support algorithms that integrate patient-specific pharmacogenetic data along with environmental and clinical variables will be essential to realizing the promise of personalized medicine.

Disclosure The authors reported no potential conflicts of interest relevant to this article.

\section{References}

Papers of particular interest, published recently, have been highlighted as:

- Of importance

1. Ansell J, Hirsh J, Hylek E, Jacobson A, Crowther M, Palareti G. Pharmacology and management of the vitamin $\mathrm{K}$ antagonists: American College of Chest Physicians Evidence-Based Clinical Practice Guidelines (8th Edition). Chest. 2008;133(6 Suppl):160 S-98S.
2. Budnitz DS, Lovegrove MC, Shehab N, Richards CL. Emergency hospitalizations for adverse drug events in older Americans. N Engl J Med. 2011;365(21):2002-12. doi:10.1056/NEJM sa1103053.

3. Sconce EA, Khan TI, Wynne HA, Avery P, Monkhouse L, King $\mathrm{BP}$, et al. The impact of CYP2C9 and VKORC1 genetic polymorphism and patient characteristics upon warfarin dose requirements: proposal for a new dosing regimen. Blood. 2005;106(7):2329-33.

4. Wadelius M, Chen LY, Eriksson N, Bumpstead S, Ghori J, Wadelius C, et al. Association of warfarin dose with genes involved in its action and metabolism. Hum Genet. 2007;121(1):23-34. doi:10.1007/s00439-006-0260-8.

5. Redman AR, Zheng J, Shamsi SA, Huo J, Kelly EJ, Ho RJ, et al. Variant CYP2C9 alleles and warfarin concentrations in patients receiving low-dose versus average-dose warfarin therapy. Clin Appl Thromb Hemost. 2008;14(1):29-37.

6. Higashi MK, Veenstra DL, Kondo LM, Wittkowsky AK, Srinouanprachanh SL, Farin FM, et al. Association between CYP2C9 genetic variants and anticoagulation-related outcomes during warfarin therapy. JAMA. 2002;287(13):1690-8.

7. Lindh JD, Holm L, Andersson ML, Rane A. Influence of CYP2C9 genotype on warfarin dose requirements-a systematic review and meta-analysis. Eur J Clin Pharmacol. 2009;65(4): 365-75. doi:10.1007/s00228-008-0584-5.

8. Cain D, Hutson SM, Wallin R. Assembly of the warfarinsensitive vitamin $\mathrm{K}$ 2,3-epoxide reductase enzyme complex in the endoplasmic reticulum membrane. J Biol Chem. 1997;272 (46):29068-75.

9. Rieder MJ, Reiner AP, Gage BF, Nickerson DA, Eby CS, McLeod HL, et al. Effect of VKORC1 haplotypes on transcriptional regulation and warfarin dose. $\mathrm{N}$ Engl $\mathrm{J}$ Med. 2005;352(22):2285-93.

10. Yuan HY, Chen JJ, Lee MT, Wung JC, Chen YF, Charng MJ, et al. A novel functional VKORC1 promoter polymorphism is associated with inter-individual and inter-ethnic differences in warfarin sensitivity. Hum Mol Genet. 2005;14(13):1745-51. doi:10.1093/hmg/ddi180.

11. Jonas DE, McLeod HL. Genetic and clinical factors relating to warfarin dosing. Trends Pharmacol Sci. 2009;30(7):375-86. doi: 10.1016/j.tips.2009.05.001.

12. Borgiani P, Ciccacci C, Forte V, Sirianni E, Novelli L, Bramanti $\mathrm{P}$, et al. CYP4F2 genetic variant (rs2108622) significantly contributes to warfarin dosing variability in the Italian population. Pharmacogenomics. 2009;10(2):261-6.

13. McDonald MG, Rieder MJ, Nakano M, Hsia CH, Rettie AE. Cyp4f2 is a vitamin K1 oxidase: an explanation for altered warfarin dose in carriers of the V433m variant. Mol Pharmacol. 2009;75(6):1337-46.

14. Sagrieya H, Berube C, Wen A, Ramakrishnan R, Mir A, Hamilton A, et al. Extending and evaluating a warfarin dosing algorithm that includes CYP4F2 and pooled rare variants of CYP2C9. Pharmacogenet Genomics. 2010;20(7):407-13. doi: 10.1097/FPC.0b013e328338bac2.

15. Takeuchi F, McGinnis R, Bourgeois S, Barnes C, Eriksson N, Soranzo N, et al. A genome-wide association study confirms VKORC1, CYP2C9, and CYP4F2 as principal genetic determinants of warfarin dose. PLoS Genet. 2009;5(3):e1000433. doi:10.1371/journal.pgen.1000433.

16. Klein TE, Altman RB, Eriksson N, Gage BF, Kimmel SE, Lee MT, et al. Estimation of the warfarin dose with clinical and pharmacogenetic data. N Engl J Med. 2009;360(8):753-64. doi: 10.1056/NEJMoa0809329.

17. Garcia DA, Lopes RD, Hylek EM. New-onset atrial fibrillation and warfarin initiation: high risk periods and implications for 
new antithrombotic drugs. Thromb Haemost. 2010;104(6):1099 -105. doi:10.1160/TH10-07-0491.

18. Schwarz UI, Ritchie MD, Bradford Y, Li C, Dudek SM, FryeAnderson A, et al. Genetic determinants of response to warfarin during initial anticoagulation. N Engl J Med. 2008;358(10): 999-1008. doi:10.1056/NEJMoa0708078.

19. Gong IY, Schwarz UI, Crown N, Dresser GK, Lazo-Langner A, Zou $\mathrm{G}$, et al. Clinical and genetic determinants of warfarin pharmacokinetics and pharmacodynamics during treatment initiation. PLoS One. 2011;6(11):e27808. doi:10.1371/journal. pone.0027808

20. Anderson JL, Horne BD, Stevens SM, Woller SC, Samuelson KM, Mansfield JW, et al. A randomized and clinical effectiveness trial comparing two pharmacogenetic algorithms and standard care for individualizing warfarin dosing (CoumaGen-II). Circulation. 2012;125(16):1997-2005. doi:10.1161/CIRCULATIONAHA. 111.070920. This article represents the latest randomized clinical trial evaluating the clinical effectiveness of pharmacogenetics-guided warfarin dosing as compared to standard care. The authors found improved primary outcomes (percent time spent in and out of INR range) in the pharmacogenetics-dosing group and concluded from the findings that genetics should be considered for clinical application.

21. Epstein RS, Moyer TP, Aubert RE, O'Kane DJ, Xia F, Verbrugge $\mathrm{RR}$, et al. Warfarin genotyping reduces hospitalization rates results from the MM-WES (Medco-Mayo Warfarin Effectiveness Study). J Am Coll Cardiol. 2010;55(25):2804-12. doi:10.1016/j.jacc.2010.03.009..

22. Fareed J, Thethi I, Hoppensteadt D. Old versus new oral anticoagulants: focus on pharmacology. Annu Rev Pharmacol Toxicol. 2012;52:79-99. doi:10.1146/annurev-pharmtox-010611-134633.

23. Gong IY, Mansell SE, Kim RB. Absence of both MDR1 (ABCB1) and BCRP (ABCG2) transporters significantly alters rivaroxaban disposition and CNS entry. Basic Clin Pharmacol Toxicol. 2012;. doi:10.1111/bcpt.12005.

24. Halushka MK, Walker LP, Halushka PV. Genetic variation in cyclooxygenase 1: effects on response to aspirin. Clin Pharmacol Ther. 2003;73(1):122-30. doi:10.1067/mcp.2003.1.

25. Hovens MM, Snoep JD, Eikenboom JC, van der Bom JG, Mertens BJ, Huisman MV. Prevalence of persistent platelet reactivity despite use of aspirin: a systematic review. Am Heart J. 2007;153(2):175-81. doi:10.1016/j.ahj.2006.10.040.

26. Verschuren JJ, Trompet S, Wessels JA, Guchelaar HJ, de Maat MP, Simoons ML, et al. A systematic review on pharmacogenetics in cardiovascular disease: is it ready for clinical application? Eur Heart J. 2012;33(2):165-75. doi:10.1093/eurheartj/ ehr239.

27. Faraday N, Yanek LR, Yang XP, Mathias R, Herrera-Galeano JE, Suktitipat B, et al. Identification of a specific intronic PEAR1 gene variant associated with greater platelet aggregability and protein expression. Blood. 2011;118(12):3367-75. doi:10.1182/blood-2010-11-320788.

28. Chasman DI, Shiffman D, Zee RY, Louie JZ, Luke MM, Rowland CM, et al. Polymorphism in the apolipoprotein(a) gene, plasma lipoprotein(a), cardiovascular disease, and low-dose aspirin therapy. Atherosclerosis. 2009;203(2):371-6. doi:10.1016/j.atherosclerosis.2008.07.019.

29. Yusuf S, Zhao F, Mehta SR, Chrolavicius S, Tognoni G, Fox KK. Effects of clopidogrel in addition to aspirin in patients with acute coronary syndromes without ST-segment elevation. N Engl J Med. 2001;345(7):494-502. doi:10.1056/NEJMoa010746.

30. Savi P, Pereillo JM, Uzabiaga MF, Combalbert J, Picard C, Maffrand JP, et al. Identification and biological activity of the active metabolite of clopidogrel. Thromb Haemost. 2000;84(5): 891-6.
31. Snoep JD, Hovens MM, Eikenboom JC, van der Bom JG, Jukema JW, Huisman MV. Clopidogrel nonresponsiveness in patients undergoing percutaneous coronary intervention with stenting: a systematic review and meta-analysis. Am Heart J. 2007;154(2):221-31. doi:10.1016/j.ahj.2007.04.014.

32. Hagihara K, Kazui M, Kurihara A, Yoshiike M, Honda K, Okazaki $\mathrm{O}$, et al. A possible mechanism for the differences in efficiency and variability of active metabolite formation from thienopyridine antiplatelet agents, prasugrel and clopidogrel. Drug Metab Dispos. 2009;37(11):2145-52. doi:10.1124/dmd. 109.028498

33. Kazui M, Nishiya Y, Ishizuka T, Hagihara K, Farid NA, Okazaki $\mathrm{O}$, et al. Identification of the human cytochrome P450 enzymes involved in the two oxidative steps in the bioactivation of clopidogrel to its pharmacologically active metabolite. Drug Metab Dispos. 2010;38(1):92-9. doi:10.1124/dmd.109.029132.

34. Mega JL, Simon T, Collet JP, Anderson JL, Antman EM, Bliden $\mathrm{K}$, et al. Reduced-function CYP2C19 genotype and risk of adverse clinical outcomes among patients treated with clopidogrel predominantly for PCI: a meta-analysis. JAMA. 2010;304(16):1821-30. doi:10.1001/jama.2010.1543.

35. Sibbing D, Koch W, Gebhard D, Schuster T, Braun S, Stegherr $\mathrm{J}$, et al. Cytochrome $2 \mathrm{C} 19 * 17$ allelic variant, platelet aggregation, bleeding events, and stent thrombosis in clopidogrel-treated patients with coronary stent placement. Circulation. 2010;121 (4):512-8. doi:10.1161/CIRCULATIONAHA.109.885194.

36. Bouman HJ, Schomig E, van Werkum JW, Velder J, Hackeng $\mathrm{CM}$, Hirschhauser C, et al. Paraoxonase-1 is a major determinant of clopidogrel efficacy. Nat Med. 2011;17(1):110-6. doi: 10.1038/nm.2281.

37. Pare G, Ross S, Mehta SR, Yusuf S, Anand SS, Connolly SJ, et al. Effect of PON1 Q192R genetic polymorphism on clopidogrel efficacy and cardiovascular events in the clopidogrel in the unstable angina to prevent recurrent events trial and the atrial fibrillation clopidogrel trial with irbesartan for prevention of vascular events. Circ Cardiovasc Genet. 2012;5(2):250-6. doi: 10.1161/CIRCGENETICS.111.961417.

38. - Gong IY, Crown N, Suen CM, Schwarz UI, Dresser GK, Knauer MJ, et al. Clarifying the importance of CYP2C19 and PON1 in the mechanism of clopidogrel bioactivation and in vivo antiplatelet response. Eur Heart J. 2012;. doi:10.1093/ eurheartj/ehs042. This article clarifies the mechanistic role of CYP2C19 vs PON1 in clopidogrel metabolism and response. The authors show that CYP2C19 is the primary contributor for clopidogrel bioactivation to the active metabolite while PON1 converts clopidogrel to an alternative inactive metabolite.

39. Dansette PM, Rosi J, Bertho G, Mansuy D. Cytochromes P450 catalyze both steps of the major pathway of clopidogrel bioactivation, whereas paraoxonase catalyzes the formation of a minor thiol metabolite isomer. Chem Res Toxicol. 2012;25(2): 348-56. doi:10.1021/tx2004085.

40. Taubert D, von Beckerath N, Grimberg G, Lazar A, Jung N, Goeser $\mathrm{T}$, et al. Impact of P-glycoprotein on clopidogrel absorption. Clin Pharmacol Ther. 2006;80(5):486-501. doi: 10.1016/j.clpt.2006.07.007.

41. Mega JL, Close SL, Wiviott SD, Shen L, Walker JR, Simon T, et al. Genetic variants in ABCB1 and CYP2C19 and cardiovascular outcomes after treatment with clopidogrel and prasugrel in the TRITON-TIMI 38 trial: a pharmacogenetic analysis. Lancet. 2010;376(9749):1312-9. doi:10.1016/S0140-6736(10) 61273-1.

42. Harmsze A, van Werkum JW, Bouman HJ, Ruven HJ, Breet NJ, Ten Berg JM, et al. Besides CYP2C19*2, the variant allele CYP2C9*3 is associated with higher on-clopidogrel platelet reactivity in patients on dual antiplatelet therapy undergoing 
elective coronary stent implantation. Pharmacogenet Genomics. 2010;20(1):18-25. doi:10.1097/FPC.0b013e328333dafe.

43. Ziegler S, Schillinger M, Funk M, Felber K, Exner M, Mlekusch $\mathrm{W}$, et al. Association of a functional polymorphism in the clopidogrel target receptor gene, P2Y12, and the risk for ischemic cerebrovascular events in patients with peripheral artery disease. Stroke J Cereb Circ. 2005;36(7):1394-9. doi: 10.1161/01.STR.0000169922.79281.a5.

44. Cuisset T, Frere C, Quilici J, Morange PE, Saut N, Lambert M, et al. Role of the T744C polymorphism of the P2Y12 gene on platelet response to a $600-\mathrm{mg}$ loading dose of clopidogrel in 597 patients with non-ST-segment elevation acute coronary syndrome. Thromb Res. 2007;120(6):893-9. doi:10.1016/j.thromres.2007.01.012.

45. Shuldiner AR, O'Connell JR, Bliden KP, Gandhi A, Ryan K, Horenstein RB, et al. Association of cytochrome P450 2C19 genotype with the antiplatelet effect and clinical efficacy of clopidogrel therapy. JAMA. 2009;302(8):849-57. doi:10.1001/ jama.2009.1232.

46. Roberts JD, Wells GA, Le May MR, Labinaz M, Glover C, Froeschl M, et al. Point-of-care genetic testing for personalisation of antiplatelet treatment (RAPID GENE): a prospective, randomised, proof-of-concept trial. Lancet. 2012;379(9827): 1705-11. doi:10.1016/S0140-6736(12)60161-5.

47. • Pulley JM, Denny JC, Peterson JF, Bernard GR, VnencakJones CL, Ramirez AH, et al. Operational implementation of prospective genotyping for personalized medicine: the design of the Vanderbilt PREDICT project. Clin Pharmacol Ther. 2012;92(1):87-95. doi:10.1038/clpt.2011.371. This article represents real-world application of genotyping for personalized clopidogrel therapy.

48. Simon T, Bhatt DL, Bergougnan L, Farenc C, Pearson K, Perrin $\mathrm{L}$, et al. Genetic polymorphisms and the impact of a higher clopidogrel dose regimen on active metabolite exposure and antiplatelet response in healthy subjects. Clin Pharmacol Ther. 2011;90(2):287-95. doi:10.1038/clpt.2011.127.

49. Mega JL, Hochholzer W, Frelinger AL 3rd, Kluk MJ, Angiolillo DJ, Kereiakes DJ, et al. Dosing clopidogrel based on CYP2C19 genotype and the effect on platelet reactivity in patients with stable cardiovascular disease. JAMA. 2011;306(20):2221-8. doi:10.1001/jama.2011.1703.

50. Scott SA, Sangkuhl K, Gardner EE, Stein CM, Hulot JS, Johnson JA, et al. Clinical Pharmacogenetics Implementation Consortium guidelines for cytochrome P450-2C19 (CYP2C19) genotype and clopidogrel therapy. Clin Pharmacol Ther. 2011;90(2):328-32. doi:10.1038/clpt.2011.132.

51. Bernlochner I, Mayer K, Morath T, Braun S, Schulz S, Schomig A, et al. High frequency of CYP2C19*2 carriers in PCI-treated patients switched over from clopidogrel to prasugrel based on platelet function monitoring. Platelets. 2012;. doi:10.3109/ 09537104.2012.715218.

52. Tantry US, Gurbel PA. Current options in oral antiplatelet strategies during percutaneous coronary interventions. Rev Cardiovasc Med. 2011;12(Suppl 1):S4-13.

53. Mangravite LM, Thorn CF, Krauss RM. Clinical implications of pharmacogenomics of statin treatment. Pharmacogenomics J. 2006;6(6):360-74. doi:10.1038/sj.tpj.6500384.

54. Niemi M. Role of OATP transporters in the disposition of drugs. Pharmacogenomics. 2007;8(7):787-802. doi:10.2217/14622416. 8.7.787.

55. Tirona RG, Leake BF, Merino G, Kim RB. Polymorphisms in OATP-C: identification of multiple allelic variants associated with altered transport activity among European- and AfricanAmericans. J Biol Chem. 2001;276(38):35669-75. doi:10.1074/ jbc.M103792200.

56. Niemi M, Backman JT, Kajosaari LI, Leathart JB, Neuvonen M, Daly $\mathrm{AK}$, et al. Polymorphic organic anion transporting polypeptide $1 \mathrm{~B} 1$ is a major determinant of repaglinide pharmacokinetics. Clin Pharmacol Ther. 2005;77(6):468-78. doi: 10.1016/j.clpt.2005.01.018.

57. Igel M, Arnold KA, Niemi M, Hofmann U, Schwab M, Lutjohann D, et al. Impact of the SLCO1B1 polymorphism on the pharmacokinetics and lipid-lowering efficacy of multiple-dose pravastatin. Clin Pharmacol Ther. 2006;79(5):419-26. doi: 10.1016/j.clpt.2006.01.010.

58. Link E, Parish S, Armitage J, Bowman L, Heath S, Matsuda F, et al. SLCO1B1 variants and statin-induced myopathy-a genomewide study. N Engl J Med. 2008;359(8):789-99. doi: 10.1056/NEJMoa0801936.

59. Voora D, Shah SH, Spasojevic I, Ali S, Reed CR, Salisbury BA, et al. The SLCO1B $1 * 5$ genetic variant is associated with statininduced side effects. J Am Coll Cardiol. 2009;54(17):1609-16. doi:10.1016/j.jacc.2009.04.053.

60. Donnelly LA, Doney AS, Tavendale R, Lang CC, Pearson ER, Colhoun HM, et al. Common nonsynonymous substitutions in SLCO1B1 predispose to statin intolerance in routinely treated individuals with type 2 diabetes: a go-DARTS study. Clin Pharmacol Ther. 2011;89(2):210-6. doi:10.1038/clpt.2010.255.

61. Voora D, Ginsburg GS. Clinical application of cardiovascular pharmacogenetics. J Am Coll Cardiol. 2012;60(1):9-20. doi: 10.1016/j.jacc.2012.01.067.

62. Donnelly LA, Doney AS, Dannfald J, Whitley AL, Lang CC, Morris $\mathrm{AD}$, et al. A paucimorphic variant in the HMG-CoA reductase gene is associated with lipid-lowering response to statin treatment in diabetes: a GoDARTS study. Pharmacogenet Genomics. 2008;18(12):1021-6. doi:10.1097/FPC.0b013e32831 06071.

63. - Thompson JF, Hyde CL, Wood LS, Paciga SA, Hinds DA, Cox DR, et al. Comprehensive whole-genome and candidate gene analysis for response to statin therapy in the Treating to New Targets (TNT) cohort. Circ Cardiovasc Genet. 2009;2(2): 173-81. doi:10.1161/CIRCGENETICS.108.818062.. This article represents a recent genome-wide association study to identify the genetic markers of statin response

64. Zintzaras E, Kitsios GD, Triposkiadis F, Lau J, Raman G. APOE gene polymorphisms and response to statin therapy. Pharmacogenomics J. 2009;9(4):248-57. doi:10.1038/tpj.2009.25.

65. Li Y, Iakoubova OA, Shiffman D, Devlin JJ, Forrester JS, Superko HR. KIF6 polymorphism as a predictor of risk of coronary events and of clinical event reduction by statin therapy. Am J Cardiol. 2010;106(7):994-8. doi:10.1016/j. amjcard.2010.05.033.

66. Iakoubova OA, Robertson M, Tong CH, Rowland CM, Catanese JJ, Blauw GJ, et al. KIF6 Trp719Arg polymorphism and the effect of statin therapy in elderly patients: results from the PROSPER study. Eur J Cardiovasc Prev Rehabil. 2010;17(4): 455-61. doi:10.1097/HJR.0b013e328336a0dd.

67. Assimes TL, Holm H, Kathiresan S, Reilly MP, Thorleifsson G, Voight BF, et al. Lack of association between the Trp719Arg polymorphism in kinesin-like protein- 6 and coronary artery disease in 19 case-control studies. J Am Coll Cardiol. 2010;56(19):1552-63. doi:10.1016/j.jacc.2010.06.022.

68. Tomlinson B, Hu M, Lee VW, Lui SS, Chu TT, Poon EW, et al. ABCG2 polymorphism is associated with the low-density lipoprotein cholesterol response to rosuvastatin. Clin Pharmacol Ther. 2010;87(5):558-62. doi:10.1038/clpt.2009.232.

69. Mangravite LM, Medina MW, Cui J, Pressman S, Smith JD, Rieder MJ, et al. Combined influence of LDLR and HMGCR sequence variation on lipid-lowering response to simvastatin. Arterioscler Thromb Vasc Biol. 2010;30(7):1485-92. doi: 10.1161/ATVBAHA.110.203273.

70. Barber MJ, Mangravite LM, Hyde CL, Chasman DI, Smith JD, McCarty CA, et al. Genome-wide association of lipid-lowering 
response to statins in combined study populations. PLoS One. 2010;5(3):e9763. doi:10.1371/journal.pone.0009763.

71. Hjalmarson A, Goldstein S, Fagerberg B, Wedel H, Waagstein F, Kjekshus J, et al. Effects of controlled-release metoprolol on total mortality, hospitalizations, and well-being in patients with heart failure: the Metoprolol CR/XL Randomized Intervention Trial in congestive heart failure (MERIT-HF). MERIT-HF Study Group. JAMA. 2000;283(10):1295-302.

72. Wuttke H, Rau T, Eschenhagen T. Genetic polymorphisms in drug metabolizing enzymes-impact on treatment with betablockers. Dtsch Med Wochenschr. 2004;129(15):831-5. doi: 10.1055/s-2004-823030.

73. Gaedigk A, Simon SD, Pearce RE, Bradford LD, Kennedy MJ, Leeder JS. The CYP2D6 activity score: translating genotype information into a qualitative measure of phenotype. Clin Pharmacol Ther. 2008;83(2):234-42. doi:10.1038/sj.clpt.6100406.

74. Rau T, Heide R, Bergmann K, Wuttke H, Werner U, Feifel N, et al. Effect of the CYP2D6 genotype on metoprolol metabolism persists during long-term treatment. Pharmacogenetics. 2002; 12(6):465-72.

75. Bijl MJ, Visser LE, van Schaik RH, Kors JA, Witteman JC, Hofman A, et al. Genetic variation in the CYP2D6 gene is associated with a lower heart rate and blood pressure in betablocker users. Clin Pharmacol Ther. 2009;85(1):45-50. doi: 10.1038/clpt.2008.172.

76. Wuttke H, Rau T, Heide R, Bergmann K, Bohm M, Weil J, et al. Increased frequency of cytochrome P450 2D6 poor metabolizers among patients with metoprolol-associated adverse effects. Clin Pharmacol Ther. 2002;72(4):429-37. doi:10.1067/mcp.2002. 127111.

77. Fux R, Morike K, Prohmer AM, Delabar U, Schwab M, Schaeffeler E, et al. Impact of CYP2D6 genotype on adverse effects during treatment with metoprolol: a prospective clinical study. Clin Pharmacol Ther. 2005;78(4):378-87. doi:10.1016/ j.clpt.2005.07.004.

78. Muthumala A, Drenos F, Elliott PM, Humphries SE. Role of beta adrenergic receptor polymorphisms in heart failure: systematic review and meta-analysis. Eur J Heart Fail. 2008;10(1): 3-13. doi:10.1016/j.ejheart.2007.11.008.

79. Johnson JA, Zineh I, Puckett BJ, McGorray SP, Yarandi HN, Pauly DF. Beta 1-adrenergic receptor polymorphisms and antihypertensive response to metoprolol. Clin Pharmacol Ther. 2003;74(1):44-52. doi:10.1016/S0009-9236(03)00068-7.

80. Karlsson J, Lind L, Hallberg P, Michaelsson K, Kurland L, Kahan T, et al. Beta1-adrenergic receptor gene polymorphisms and response to beta1-adrenergic receptor blockade in patients with essential hypertension. Clin Cardiol. 2004;27(6):347-50.

81. Liggett SB, Mialet-Perez J, Thaneemit-Chen S, Weber SA, Greene SM, Hodne D, et al. A polymorphism within a conserved beta(1)-adrenergic receptor motif alters cardiac function and betablocker response in human heart failure. Proc Natl Acad Sci USA. 2006;103(30):11288-93. doi:10.1073/pnas.0509937103.

82. White HL, de Boer RA, Maqbool A, Greenwood D, van Veldhuisen DJ, Cuthbert R, et al. An evaluation of the beta-1 adrenergic receptor Arg389Gly polymorphism in individuals with heart failure: a MERIT-HF sub-study. Eur J Heart Fail. 2003;5(4):463-8.

83. Cresci S, Kelly RJ, Cappola TP, Diwan A, Dries D, Kardia SL, et al. Clinical and genetic modifiers of long-term survival in heart failure. J Am Coll Cardiol. 2009;54(5):432-44. doi: 10.1016/j.jacc.2009.05.009.

84. Parvez B, Chopra N, Rowan S, Vaglio JC, Muhammad R, Roden $\mathrm{DM}$, et al. A common beta1-adrenergic receptor polymorphism predicts favorable response to rate-control therapy in atrial fibrillation. J Am Coll Cardiol. 2012;59(1):49-56. doi:10.1016/ j.jacc.2011.08.061.
85. Sehrt D, Meineke I, Tzvetkov M, Gultepe S, Brockmoller J. Carvedilol pharmacokinetics and pharmacodynamics in relation to CYP2D6 and ADRB pharmacogenetics. Pharmacogenomics. 2011;12(6):783-95. doi:10.2217/pgs.11.20.

86. de Groote P, Helbecque N, Lamblin N, Hermant X, Mc Fadden E, Foucher-Hossein C, et al. Association between beta- 1 and beta-2 adrenergic receptor gene polymorphisms and the response to beta-blockade in patients with stable congestive heart failure. Pharmacogenet Genomics. 2005;15(3):137-42.

87. Pacanowski MA, Gong Y, Cooper-Dehoff RM, Schork NJ, Shriver MD, Langaee TY, et al. Beta-adrenergic receptor gene polymorphisms and beta-blocker treatment outcomes in hypertension. Clin Pharmacol Ther. 2008;84(6):715-21. doi: 10.1038/clpt.2008.139.

88. Troncoso R, Moraga F, Chiong M, Roldan J, Bravo R, Valenzuela R, et al. Gln(27) $\rightarrow$ Glubeta(2)-adrenergic receptor polymorphism in heart failure patients: differential clinical and oxidative response to carvedilol. Basic Clin Pharmacol Toxicol. 2009;104(5):374-8.

89. Petersen M, Andersen JT, Hjelvang BR, Broedbaek K, Afzal S, Nyegaard M, et al. Association of beta-adrenergic receptor polymorphisms and mortality in carvedilol-treated chronic heart-failure patients. Br J Clin Pharmacol. 2011;71(4):556-65. doi:10.1111/j.1365-2125.2010.03868.x.

90. Littlejohn MD, Palmer BR, Richards AM, Frampton CM, Pilbrow AP, Troughton RW, et al. Ile164 variant of beta2adrenoceptor does not influence outcome in heart failure but may interact with beta blocker treatment. Eur J Heart Fail. 2008;10(1):55-9. doi:10.1016/j.ejheart.2007.10.011.

91. Lobmeyer MT, Gong Y, Terra SG, Beitelshees AL, Langaee TY, Pauly DF, et al. Synergistic polymorphisms of beta1 and alpha2C-adrenergic receptors and the influence on left ventricular ejection fraction response to beta-blocker therapy in heart failure. Pharmacogenet Genomics. 2007;17(4):277-82. doi: 10.1097/FPC.0b013e3280105245.

92. Small KM, Forbes SL, Rahman FF, Bridges KM, Liggett SB. A four amino acid deletion polymorphism in the third intracellular loop of the human alpha 2C-adrenergic receptor confers impaired coupling to multiple effectors. J Biol Chem. 2000;275 (30):23059-64. doi:10.1074/jbc.M000796200.

93. Liggett SB, Cresci S, Kelly RJ, Syed FM, Matkovich SJ, Hahn HS, et al. A GRK5 polymorphism that inhibits beta-adrenergic receptor signaling is protective in heart failure. Nat Med. 2008;14(5):510-7. doi:10.1038/nm1750.

94. Barsheshet A, Goldenberg I, O-Uchi J, Moss AJ, Jons C, Shimizu W, et al. Mutations in cytoplasmic loops of the KCNQ1 channel and the risk of life-threatening events: implications for mutation-specific response to beta-blocker therapy in type 1 long-QT syndrome. Circulation. 2012;125(16):1988-96. doi: 10.1161/CIRCULATIONAHA.111.048041.

95. - Swen JJ, Nijenhuis M, de Boer A, Grandia L, Maitland-van der Zee $\mathrm{AH}$, Mulder $\mathrm{H}$, et al. Pharmacogenetics: from bench to byte-an update of guidelines. Clin Pharmacol Ther. 2011;89(5):662-73. doi:10.1038/clpt.2011.34. This article provides guidelines for the clinical application of pharmacogenetics for a variety of cardiovascular medications. The guideline recommends either dose adjustment or alternative therapy for individuals harboring susceptible genetic variations.

96. Konoshita T. Do genetic variants of the Renin-Angiotensin system predict blood pressure response to Renin-Angiotensin system-blocking drugs?: a systematic review of pharmacogenomics in the Renin-Angiotensin system. Curr Hypertens Rep. 2011;13(5):356-61. doi:10.1007/s11906-011-0212-0.

97. Brugts JJ, Isaacs A, Boersma E, van Duijn CM, Uitterlinden AG, Remme W, et al. Genetic determinants of treatment benefit of the angiotensin-converting enzyme-inhibitor perindopril in 
patients with stable coronary artery disease. Eur Heart J. 2010;31(15):1854-64. doi:10.1093/eurheartj/ehq169.

98. Li YF, Zhu XM, Liu F, Xiao CS, Bian YF, Li H, et al. Angiotensinconverting enzyme (ACE) gene insertion/deletion polymorphism and ACE inhibitor-related cough: a meta-analysis. PLoS One. 2012;7(6):e37396. doi:10.1371/journal.pone.0037396.

99. Schelleman H, Klungel OH, Witteman JC, Breteler MM, Yazdanpanah M, Danser AH, et al. Angiotensinogen M235T polymorphism and the risk of myocardial infarction and stroke among hypertensive patients on ACE-inhibitors or beta-blockers. Eur J Hum Genet. 2007;15(4):478-84. doi:10. 1038/sj.ejhg.5201789.

100. Su X, Lee L, Li X, Lv J, Hu Y, Zhan S, et al. Association between angiotensinogen, angiotensin II receptor genes, and blood pressure response to an angiotensin-converting enzyme inhibitor. Circulation. 2007;115(6):725-32. doi:10.1161/CIRCULATIONAHA.106. 642058.

101. Darbar D, Roden DM. Pharmacogenetics of antiarrhythmic therapy. Expert Opin Pharmacother. 2006;7(12):1583-90. doi: 10.1517/14656566.7.12.1583. 